\title{
Analisis Kelayakan Project Loon di Indonesia
}

\author{
SETIYO BUDIYANTO, MUHAMMAD JAMIL, FAJAR RAHAYU
}

Teknik Elektro Universitas Mercu Buana

Email: sbudiyanto@mercubuana.ac.id

Received 17 Maret 2019 | Revised 29 Maret 2019 | Accepted 9 April 2019

\begin{abstract}
ABSTRAK
Indonesia merupakan Negara kepulauan yang terdiri dari ribuan pulau. Kondisi geografis tersebut membuat layanan internet di Indonesia belum sepenuhnya merata. Tercatat, pengguna internet area perkotaan, antara desa dan kota, serta pedesaan berturut sebesar72,41\%, 49,5\%, dan 48,3\%. Berikut komposisi dari pengguna internet di Indonesia: pulau Jawa, Sumatera, Kalimantan, Sulawesi, Bali-Nusa Tenggara, dan Maluku-Papua masing-masing sebesar 58,1\%,19\%, $8 \%, 6,7 \%, 5,6 \%$, dan 2,5\%. Guna mengatasi masalah ini, beberapa upaya telah dilakukan untuk menyamakan akses internet di Indonesia, dan salah satu upaya yang ditawarkan adalah Project Loon. Project Loon merupakan teknologi komunikasi berdasarkan High Altitude Platform (HAPs). Penelitian terkait pengujian kelayakan Project Loon dilakukan menggunakan studi literatur Kemudian digunakan metode Alogritma Fuzzy Topsis untuk mengukur Ekuensi Pathloss, Bandwith Fuzzy, Utilitas Frekuensi, sehingga diperoleh matrik keputusan dan matrik pembobotan yang menunjukkan frekuensi terbaik yang dapat digunakan adalah frekuensi $700 \mathrm{MHz}$ dengan nilai 0.58307. frekuensi ini dipilih secara otomatis berdasarkan kriteria jarak, bandwidth, dan aplikasi-aplikasi yang berjalan pada frekuensi tersebut.
\end{abstract}

Kata Kunci : Project Loon, HAPs, Algoritma Fuzzy Topsis

\begin{abstract}
Indonesia is an archipelago consisting of many islands. This geographical condition makes internet services in Indonesia not yet evenly distributed. Noted, internet users in urban areas, between villages and cities, as well as rural areas amounted to $72.41 \%, 49.5 \%$, and $48.3 \%$. The following is the composition of internet users in Indonesia: Java, Sumatra, Kalimantan, Sulawesi, Bali-Nusa Tenggara, and Maluku-Papua, respectively 58.1\%, 19\%, 8\%, 6.7\%, $56 \%$ and $2.5 \%$. To overcome this problem, several attempts have been made to equalize internet access in Indonesia, and one of the efforts offered is Project Loon. Project Loon is a communication technology based on High Altitude Platform (HAPs). Research related to Project Loon eligibility testing was conducted using literature studies. Then we use the Alogritma Fuzzy Topsis method to measure Pathloss Equity, Fuzzy Bandwidth, Frequency Utility, the required matrix and the weighting matrix used are $700 \mathrm{MHz}$ frequencies with a value of 0.58307. Based on frequency, bandwidth, and applications running on that frequency.
\end{abstract}

Keywords: Project Loon, HAPs, Algoritma Fuzzy Topsis

$$
\text { ELKOMIKA - } 392
$$


Analisis Kelayakan Project Loon di Indonesia

\section{PENDAHULUAN}

Indonesia merupakan Negara yang luas terdiri dari ribuan pulau yang tersebar dari Sabang sampai Merauke. Kondisi geografis Indonesia tersebut menjadi suatu kendala dalam pelayanan teknologi informasi khususnya internet bagi masyarakat. Hasil survei Asosiasi Penyelenggara Jaringan Internet Indonesia (APJII) bekerja sama dengan Teknologi Indonesia, menunjukkan pengguna internet di Indonesia masih tidak merata dan hanya terfokus di daerah perkotaan. Data tersebut menunjukkan sebesar $72,41 \%$ penduduk perkotaan bisa mengakses internet. Sementara itu, di daerah pedesaan-perkotaan atau daerah antara desa dan kota, hanya 49,5\% yang terhubung ke internet. Sementara di pedesaan hanya $48,3 \%$ yang terhubung ke internet. Menurut wilayah, komposisi pengguna internet terbesar ada di Jawa, yaitu 58,1\%. Setelah itu di Sumatera dengan komposisi 19\% dan Kalimantan 8\%. Sedangkan daerah lain, yaitu Sulawesi, Bali-Nusa Tenggara, dan Maluku-Papua masing-masing memiliki komposisi 6,7\%, 5,6\%, dan 2,5\% (APJII, 2018).

Di sisi lain, lalu lintas data telah meningkat sebesar $131 \%$ sejak 2011 . Ini telah mendorong beberapa operator seluler di Eropa untuk berinvestasi dalam komunikasi mesin-ke-mesin. Namun, jaringan seluler yang ada tidak dapat mengakomodasi pertumbuhan eksponensial dalam lalu lintas data (Budiyanto, 2014). Hal ini adalah latar belakang teknologi yang membongkar lalu lintas seluler. Kondisi saat ini, penyedia selalu berusaha memberikan layanan terbaik kepada pengguna. Ini mempengaruhi kondisi pelanggan dengan memanfaatkan WiFi yang membongkar lalu lintas seluler yang jauh dari infrastruktur yang tersedia. Penyedia harus terus memberikan layanan terbaik kepada pelanggan dengan menyediakan Wireless Access Gateway (WAG) agar koneksi pengguna ke Gateway dapat dioptimalkan (Asvial, 2014).

Sebuah raksasa teknologi Google, menawarkan sebuah solusi untuk pemerataan jangkauan internet ke seluruh dunia. Melalui inkubasi Google X, Google mencoba melakukan terobosan dengan menghadirkan Project Loon. Dalam rilis resmi Google, Project Loon ini mampu memberikan layanan internet dan menjangkau pelosok-pelosok dan daerah terpencil sekalipun (Google, 2019). Project Loon sendiri merupakan teknologi yang mengadopsi sistem komunikasi HAPs yang menggunakan balon sebagai wahananya untuk diterbangkan pada ketinggian stratosfer yaitu sekitar 20 kilometer atau setara dengan 6000 kaki.

Di ketinggian stratosfer tersebut balon google akan membentuk jaringan luas yang saling terintegrasi antar setiap balon dengan balon lainnya. Balon tersebut dilengkapi dengan teknologi canggih seperti Artificial Intelligence yang mampu membaca dan beradaptasi dengan arah angin sehingga mampu mengatur posisinya sendiri pada arah yang lebih baik. Tidak hanya itu, balon Google juga dilengkapi dengan perangkat-perangkat elektronik seperti panel surya yang berfungsi sebagai pengisi daya yang menjamin perangkat-perangkat elektronik tetap dapat bekerja selama berbulan-bulan (Propper, 2015).

Beberapa perusahaan di dunia ini telah melakukan pengembangan mengenai teknologi HAPs. Namun hal yang berbeda dengan project loon ini adalah penggunaan balon raksasa dengan ukuran panjang 15 meter dan lebar 12 meter sebagai komponen yang membuat benda itu bisa terbang. Balon tersebut diistilahkan sebagai sampul yang diisi dengan gas helium yang dilengkapi sistem otomatis untuk memompa atau mengeluarkan udara mengikuti keadaan suhu disekitar (Katikala, 2014). Sampul balon ini dirancang khusus dari bahan plastik polietilen yang diklaim oleh Google sendiri bisa bertahan dari sinar UV sampai 100 hari di ketinggian udara. Sampul balon ini pula yang akan menjadi beban biaya rutin jika dioperasikan (Google, 2019). Balon tersebut membawa perangkat-perangkat elektronik dan komunikasi untuk memancarkan internet pada pengguna di daratan. 
Balon Google akan membentuk topologi mesh dengan rangkaian spesifikasi kendali IEEE802.11s. Ada dua jenis komunikasi: 1) Komunikasi balon ke balon, 2) komunikasi balon ke darat (Burr, 2017).

Di Indonesia, penelitian mengenai Project Loon telah dilakukan beberapa akademisi salahsatunya penelitian yang dilaksanakan oleh Puslitbang SDPPPI, Badan Penelitian dan Pengembangan Sumber Daya Manusia-Kementerian Komunikasi dan Informatika. Dalam kajian tersebut menjelaskan bahwa faktor keamanan merupakan hal yang paling penting untuk diperhatikan pada penerapan Project Loon ini, utamanya keamanan informasi dan ruang udara. Jika kedua hal ini tidak terpenuhi maka penerapan Project Loon tidak memungkinkan untuk dilaksanakan. Terdapat opsi lain untuk penerapan Project Loon ini namun ada beberapa syarat yang harus dipenuhi yaitu peluncuran dan sistem kendali balon harus dilakukan di wilayah Indonesia. Namun demikian tetap diperlukan perubahan regulasi ataupun regulasi baru yang secara terperinci menjelaskan standar dan operasional untuk menjamin tata kelola frekuensi, keamanan, dan ruang udara nasional. (Yuniarti, 2016). Penelitian ini dilakukan untuk memeriksa kelayakan penerapan Google Balloon di Indonesia dengan studi literatur dengan menggunakan metode Algoritma Fuzzy Topsis. Dengan demikian, penelitian ini diharapkan dapat mengukur potensi frekuensi penerapan balon Google jika diterapakan sebagai sistem komunikasi alternatif di Indonesia.

\subsection{Spesifikasi Google Balloon}

Dalam penelitian ini, kita akan melihat spesifikasi material apa saja yang digunakan Balon Google yang dapat kita lihat pada Tabel 1 berikut:

Tabel 1. Material untuk Setiap Balon (Burr, 2017)

\begin{tabular}{|c|c|c|c|}
\hline Komponen & Spesifikasi & Material & Total (Kg) \\
\hline \multirow[b]{2}{*}{ Sampul } & \multirow{2}{*}{$\begin{array}{l}\text { Balon } 12 \mathrm{~m} \times 15 \mathrm{~m} \text { dengan } \\
\text { ketebalan } 100 \mu \mathrm{m}\end{array}$} & Plastik polyethylene & $1170 \mathrm{~m}^{2}$ \\
\hline & & Densitas $0,95 \mathrm{~g} / \mathrm{cm} 3$ & $111,5 \mathrm{Kg}$ \\
\hline \multirow{8}{*}{$\begin{array}{l}\text { Elektronik (antena } \\
\text { dan Peralatan } \\
\text { transmisi lainnya) }\end{array}$} & \multirow{8}{*}{$\begin{array}{l}\text { Diperkirakan sebagai } 4 \text { komputer } \\
\text { desktop }\end{array}$} & Aluminium & $4,368 \mathrm{Kg}$ \\
\hline & & Plastik & $7,176 \mathrm{Kg}$ \\
\hline & & Besi & $6,552 \mathrm{Kg}$ \\
\hline & & Tembaga & $2,184 \mathrm{Kg}$ \\
\hline & & Kaca & $7,800 \mathrm{Kg}$ \\
\hline & & Nikel & $0,312 \mathrm{Kg}$ \\
\hline & & Timah & $0,312 \mathrm{Kg}$ \\
\hline & & Arang & $1,872 \mathrm{Kg}$ \\
\hline \multirow{4}{*}{ Panel Surya } & Estimated 2 & Silikon & $14 \mathrm{Kg}$ \\
\hline & Panel @20kg & Aluminium & $16 \mathrm{Kg}$ \\
\hline & & Tembaga & $2 \mathrm{Kg}$ \\
\hline & & Plastik & $8 \mathrm{Kg}$ \\
\hline Baterai & 12V Ion Lithium 200AH & & $33 \mathrm{Kg}$ \\
\hline \multirow[t]{2}{*}{ Tabung Gas } & Berdasarkan pada Praxair 128bar & Silinder & $30 \mathrm{Kg}$ \\
\hline & Tekanan Silinder & $\begin{array}{l}\text { Hidrogen }\left(1.8 \mathrm{~m}^{3} \text { at }\right. \\
13.8 \mathrm{MPa})\end{array}$ & $18,65 \mathrm{Kg}$ \\
\hline Parasut & $\begin{array}{l}\text { Berdasarkan Mills G-12E cargo } \\
\text { Parasut }\end{array}$ & $\begin{array}{l}\text { Nylon (Victoria } \\
\text { University, n.d.) }\end{array}$ & $57 \mathrm{Kg}$ \\
\hline \multicolumn{3}{|l|}{ Total } & $320,73 \mathrm{Kg}$ \\
\hline
\end{tabular}


Dengan mengetahui spesifikasi Google Balloon ini sebagaimana dapat dilihat pada Tabel 1, kita bisa mendapatkan gambaran tentang kapasitas balon, perangkat yang digunakan, beban massal.

\subsection{Perbandingan Google Balloon di Beberapa Negara}

Beberapa negara yang telah melakukan uji coba Project Loon, dapat dilihat pada Tabel 2.

Tabel 2. Google Balloon di Berbagai Negara

\begin{tabular}{|c|c|c|c|c|c|c|}
\hline No & Negara & $\begin{array}{c}\text { Jumlah } \\
\text { Balon }\end{array}$ & $\begin{array}{l}\text { Luas } \\
\text { Cakupan }\end{array}$ & Frekuensi & Status & Tahun \\
\hline 1 & $\begin{array}{c}\text { Selandia } \\
\text { Baru }\end{array}$ & 30 & $\begin{array}{c}20 \\
\text { kilometer }\end{array}$ & $\begin{array}{l}\text { ISM Band }(2.4 \mathrm{GHz} \\
\text { and } 5.8 \mathrm{GHz})\end{array}$ & Uji Coba & 2013 \\
\hline 2 & Brazil & 5 & $\begin{array}{c}30 \\
\text { kilometer }\end{array}$ & $\begin{array}{c}\text { Menggunakan } \\
\text { spektrum yang } \\
\text { dilisensikan LTE }\end{array}$ & Uji Coba & 2014 \\
\hline 3 & Australia & 20 & - & $2.6 \mathrm{GHz}$ & Uji Coba & \\
\hline 4 & $\begin{array}{c}\text { Sri } \\
\text { Lanka }\end{array}$ & 3 & - & $700 \mathrm{MHz}$ & Uji Coba & \\
\hline 5 & India & - & - & $2500 \mathrm{MHz}$ & Uji Coba & \\
\hline 6 & Peru & - & $\begin{array}{c}40 \\
\text { kilometer }\end{array}$ & $\begin{array}{c}\text { Menggunakan } \\
\text { spektrum yang } \\
\text { dilisensikan LTE }\end{array}$ & $\begin{array}{l}\text { Penanganan } \\
\text { Bencana }\end{array}$ & 2017 \\
\hline 7 & $\begin{array}{l}\text { Puerto } \\
\text { Rico }\end{array}$ & & & $\begin{array}{c}\text { Menggunakan } \\
\text { spektrum yang } \\
\text { dilisensikan LTE }\end{array}$ & $\begin{array}{l}\text { Penanganan } \\
\text { Bencana }\end{array}$ & 2017 \\
\hline
\end{tabular}

Tabel 2 menunjukkan perbandingan penerapan Google Balloon di beberapa negara. rata-rata masih dalam tahap uji coba dan tidak ada negara yang menerapkan Google Balloon secara komersial.

\section{METODOLOGI}

Dalam melakukan penelitian ini, beberapa langkah kerja sistematis dan terstruktur diterapkan untuk mendapatkan hasil yang diharapkan. Langkah-langkah yang digunakan dalam penelitian ini terlihat dalam bagan alur penelitian seperti ditunjukan pada Gambar 1. 


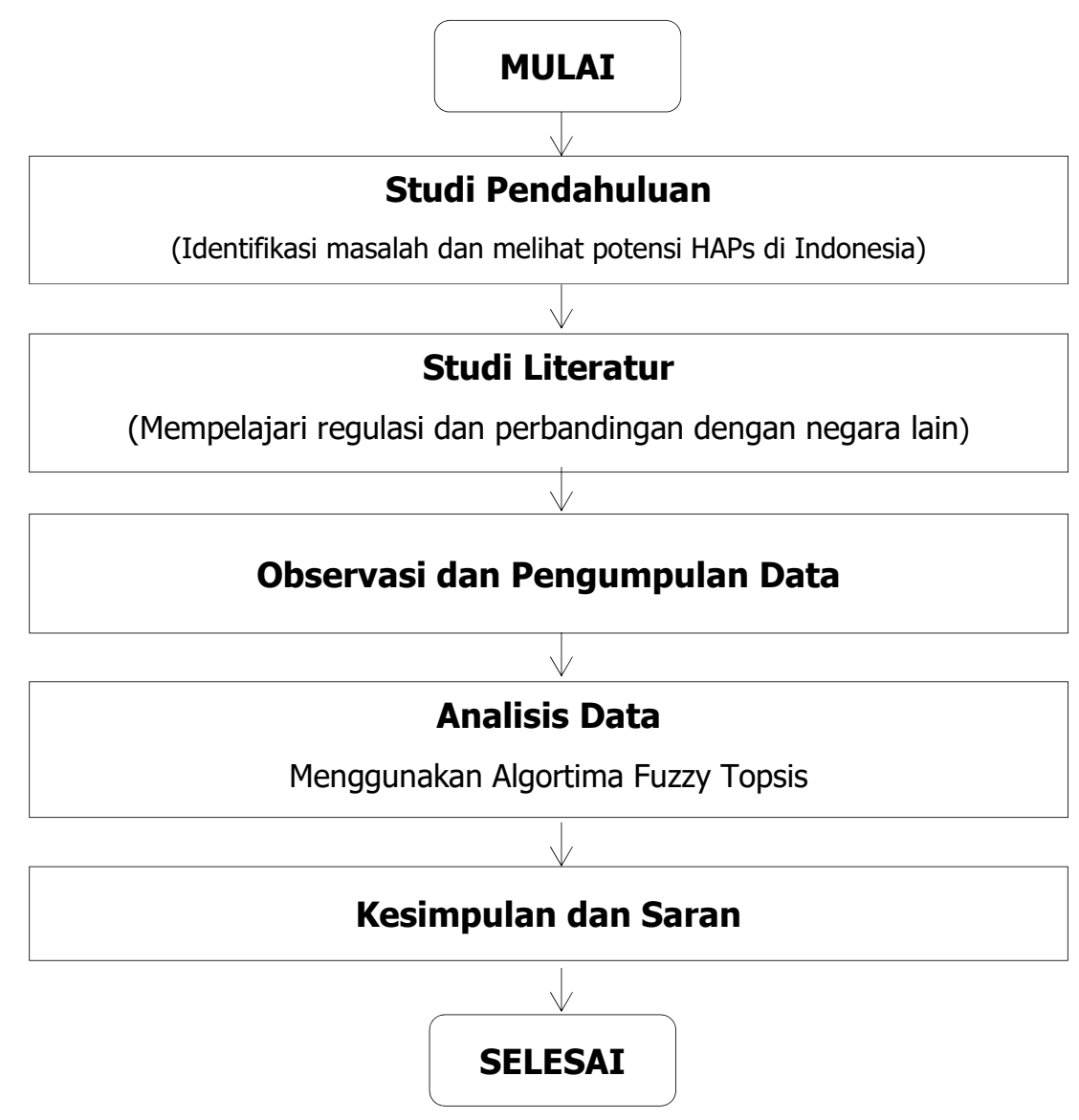

Gambar 1. Bagan Alir Penelitian

Langkah penelitian ini dimulai dengan studi pendahuluan untuk melihat potensi HAPs di Indonesia. Selanjutnya langkah kedua adalah studi literatur untuk melihat regulasi yang ada di Indonesia dan membandingkannya dengan negara lain. Dari studi literatur ini, kita bisa melihat sejauh mana perkembangan Google Balloon di dunia. Langkah ketiga adalah mengumpulkan data dari berbagai sumber. Dan selanjutnya langkah keempat adalah analisis data menggunakan Algoritma Fuzzy Topsis untuk mengukur frekuensi ideal yang digunakan Project Loon. Sehingga pada akhir penelitian ditemukan kesimpulan dan rekomendasi.

Ada beberapa langkah yang dilakukan dalam Algortima Fuzzy Topsis yaitu: membuat matriks keputusan sebagai fungsi pengamatan, melakukan normalisasi matrik keputusan. Kemudian dilakukan matrik pembobotan. Selanjutnya menentukan alternatif terburuk dan alternatif terbaik. Dan yang terakhir menghitung koefisien kedekatan. Adapun langkah-langkah analisis Fuzzy Topsis ini ditunjukkan pada Gambar 2. 


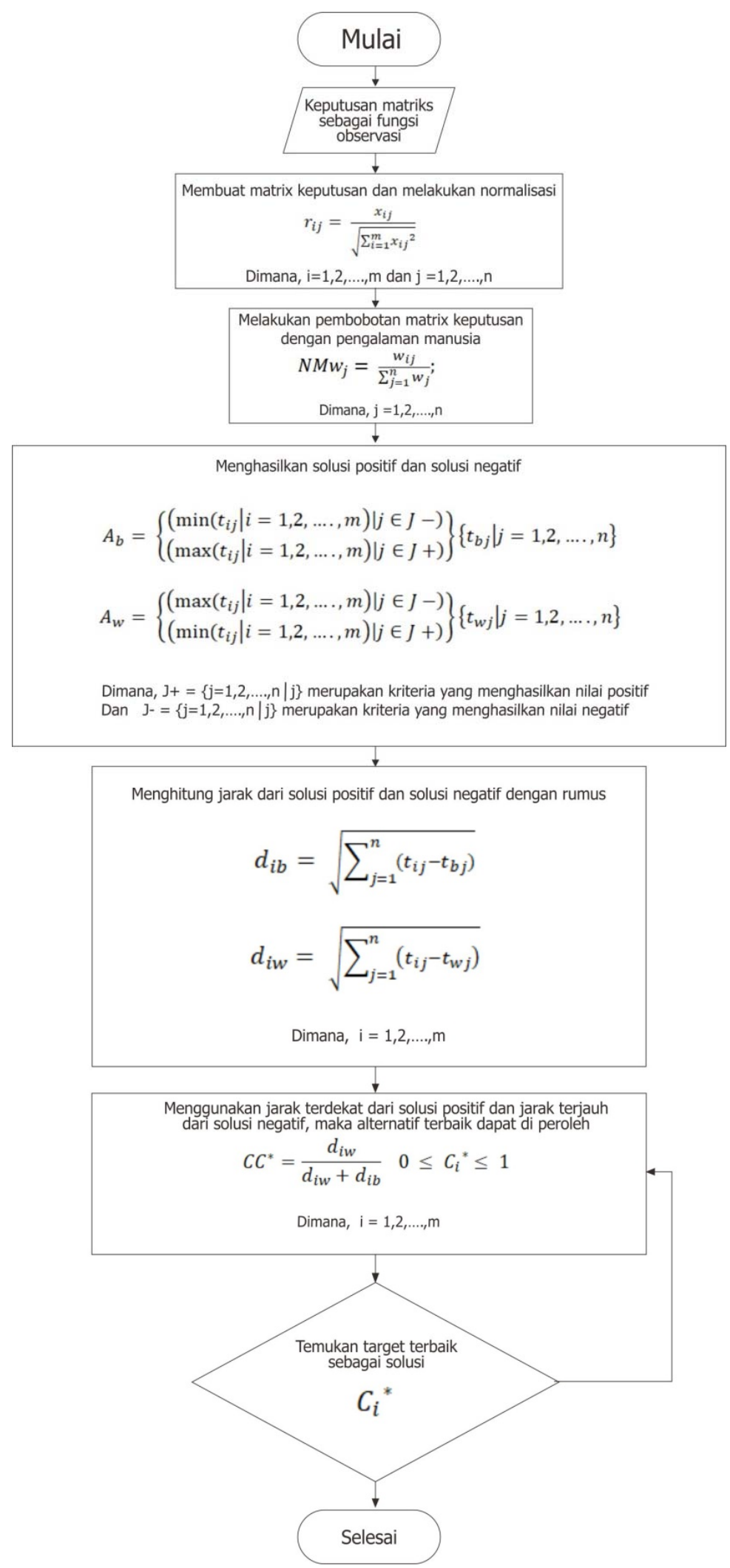

Gambar 2. Diagram Alir Algoritma Fuzzy Topsis

ELKOMIKA - 397 
Gambar 2 menunjukkan flowchart Algoritma Fuzzy Topsis untuk menentukan frekuensi terbaik yang dapat digunakan pada project loon ini. Fuzzy Topsis adalah alat untuk menyelesaikan masalah umum yang meniru pemahaman manusia untuk menentukan mana yang harus dipilih jika ada banyak alternatif dengan banyak kriteria (Hakim, 2018).

Langkah-langkah dalam Algoritma Fuzzy Topsis yaitu sebagai berikut:

1. Langkah 1: Matriks keputusan sebagai fungsi pengamatan Langkah ini menetukan matrik keputusan berdasarkan nilai-nilai linguistik. Matrik keputusan dilihat dari Konversi Frekuensi Pathloss, Bandwith Fuzzy, dan Utilitas Frekuensi.

2. Langkah 2: Normalisasi matrik keputusan Langkah ini berdasarkan nilai-nilai linguistik.

3. Langkah 3: Matrik Pembobotan berdasarkan pengalaman pengguna Langkah ini menggunakan teori Shannon Entropy untuk menentukan nilai dari normalisasi matrik keputusan dan pembobotan

4. Langkah 4: Menentukan alternatif terburuk dan alternatif terbaik Langkah ini akan menentukan masing-masing nilai jarak antara alternatif sasaran dengan kriteria yang memiliki dampak yang paling positif.

5. Langkah 5: Menghitung koefisien kedekatan Langkah ini koefisien kedekatan dihitung setelah ditentukan alternatif terburuk dan alternatif terbaik sehingga nantinya diperoleh hasil frekuensi terbaik.

\section{ANALISIS ALGORITMA FUZZY TOPSIS}

Beberapa langkah dalam analisis Fuzzy Topsis yaitu simulasi, kemudian menentukan matrik keputusan, setelah itu menentukan matrik pembobotan.

\subsection{Simulasi Menggunakan Algoritma Fuzzy Topsis}

Menggunakan Algoritma Fuzzy Topsis kita dapat mensimulasikan dan menghitung nilai untuk setiap masing-masing pemasok untuk setiap kriteria-kriteria yang diberikan oleh pengguna. Untuk dapat membuat matrik keputusan maka perlu dibuat nilai-nilai berdasarkan linguistik fuzzy. Pada penelitian ini terdapat 3 buah kriteria seperti Luas cakupan, Bandwidth dan Utilitas Frekuensi

Untuk luas cakupan kita dapat menghitung dengan menggunakan rumus free space path loss model yaitu :

$$
20 \log (d)+20 \log (f)-147.55
$$

Tabel 3. Konversi Frekuensi Pathloss

\begin{tabular}{|c|c|c|}
\hline Frekuensi (MHz) & Score Luas Cakupan & Loss (-dbm) \\
\hline 700 & 4.59 & -56 \\
\hline 900 & 4.36 & -59 \\
\hline 2400 & 3.84 & -67 \\
\hline 5800 & 3.43 & -75 \\
\hline
\end{tabular}


Tabel 3 menunjukkan konversi frekuensi menjadi pathloss sehingga hanya 20 log $\mathrm{f}$ saja. sehingga dapat kita buat tabel untuk fuzzy linguistiknya.

Tabel 4. Bandwith Fuzzy

\begin{tabular}{|c|c|c|}
\hline Frekuensi (MHz) & Bandwidth Fuzzy Linguistik & Nilai \\
\hline 700 & Kecil & 1 \\
\hline 900 & Cukup Kecil & 2 \\
\hline 2400 & menengah & 3 \\
\hline 5800 & Besar & 4 \\
\hline
\end{tabular}

Tabel 4 menunjukkan bandwidth Tabel untuk fuzzy linguistik yang dibuat berdasarkan semakin besar frekuensinya, maka bandwidth juga akan semakin besar, maka dapat di buat berdasarkan pengalaman pengguna.

Tabel 5. Utilitas Frekuensi

\begin{tabular}{|c|c|c|}
\hline $\begin{array}{c}\text { Frekuensi } \\
\text { (MHz) }\end{array}$ & Utility Frekuensi Fuzzy Linguistik & Nilai \\
\hline 700 & Penuh Frekuensi TV & 4 \\
\hline 900 & Hanya Frekuensi GSM, LoRa & 3 \\
\hline 2400 & ISM Band, Wifi, Bluethooth, Penuh & 1 \\
\hline 5800 & ISM Band, Wifi, Bluethooth, Penuh & 1 \\
\hline
\end{tabular}

Tabel 5 menujukkan utilitas frekuensi tabel untuk fuzzy linguistiknya dibuat berdasarkan interferensi dengan aplikasi yang sudah ada sebelumnya. apabila penggunaan frekuensinya terbatas untuk 1 buat aplikasi saja maka nilai linguistiknya paling besar, dan semakin banyak aplikasi pada frekuensi tersebut maka nilainya semakin kecil.

\subsection{Matrik keputusan}

Dengan menggunakan Tabel 3, Tabel 4 dan Tabel 5, maka matriks keputusan berdasarkan nilai-nilai linguistiknya dapat ditunjukkan pada Tabel 6 berikut :

Tabel 6. Matriks Keputusan Berdasarkan Nilai-nilai Linguistik

\begin{tabular}{|c|c|c|c|}
\hline Frekuensi (MHz) & Luas Cakupan & Bandwidth & $\begin{array}{c}\text { Utilitas } \\
\text { Frekuensi }\end{array}$ \\
\hline 700 & 4.59 & 1 & 4 \\
\hline 900 & 4.36 & 2 & 3 \\
\hline 2400 & 3.84 & 3 & 1 \\
\hline 5800 & 3.43 & 4 & 1 \\
\hline
\end{tabular}

Tabel 6 menunjukkan matriks keputusan berdasarkan nilai-nilai linguistik. Sehingga dapat dilihat normalisasi dari matrik keputusannya. 
Tabel 7. Normalisasi Dari Matrik Keputusan

\begin{tabular}{|c|r|r|r|}
\hline Frekuensi (MHz) & Luas Cakupan & Bandwidth & $\begin{array}{c}\text { Utilitas } \\
\text { Frekuensi }\end{array}$ \\
\hline 700 & 0.74388 & 0.16209 & 0.64836 \\
\hline 900 & 0.77034 & 0.35370 & 0.53054 \\
\hline 2400 & 0.77160 & 0.60347 & 0.20116 \\
\hline 5800 & 0.63917 & 0.74611 & 0.18653 \\
\hline
\end{tabular}

Tabel 7 menunjukkan normalisasi matrik keputusan berdasarkan nilai-nilai linguistik. Kemudian akan ditentukan matrik pembobotannya.

\subsection{Matrik Pembobotan}

Pembobotan adalah penekanan untuk kriteria yang memiliki efek terbesar untuk pengguna. Bobot ini dapat diturunkan dari konsep teorema Shannon Entropy (Dammak, 2015) atau bobot dapat didasarkan pada permintaan pengguna (Hwang, 1993). Untuk bobot menggunakan konsep teorema Shannon Entropy adalah:

$$
N M w_{j}=\frac{w_{i j}}{\sum_{j=1}^{n} w_{j}}
$$

Tabel 8. Matrik Pembobotan Berdasarkan Shannon Entropy

\begin{tabular}{|c|c|c|c|}
\hline Item & $\begin{array}{c}\text { Luas } \\
\text { Cakupan }\end{array}$ & Bandwidth & $\begin{array}{c}\text { Utilitas } \\
\text { Frekuensi }\end{array}$ \\
\hline Linguistic Weight Interval & 0.5 & 0.17 & 0.33 \\
\hline
\end{tabular}

Tabel 8 menunjukkan pembobotan berdasarkan Shannon Entropy. Terdapat Liguistic Weight Interva/ dengan luas cakupan 0.5 bandwith 0.17 dan utilitas frekuensi 0.33 .

Tabel 9. Matrik Keputusan Dengan Normalisasi dan Pembobotan

\begin{tabular}{|c|c|c|c|}
\hline Konsultan & Luas Cakupan & Bandwidth & $\begin{array}{c}\text { Utilitas } \\
\text { Frekuensi }\end{array}$ \\
\hline 700 & 0.37194 & 0.02702 & 0.21612 \\
\hline 900 & 0.38517 & 0.05895 & 0.17685 \\
\hline 2400 & 0.38580 & 0.10058 & 0.06705 \\
\hline 5800 & 0.31958 & 0.12435 & 0.06218 \\
\hline
\end{tabular}

Pada Tabel 9 menunjukkan matrik keputusan yang sudah di normalisasi dan di berikan pembobotan.

Dengan demikian untuk solusi ideal positifnya menggunakan bobot dari matrik keputusan yang telah di normalisasi dan menggunakan operator Min-max, maka solusi ideal positif ditunjukkan di bawah ini:

$\mathrm{y} 1+=\min \{0.37194 ; 0.38517 ; 0.38580 ; 0.31958\}=0.31958$

$\mathrm{y} 2+=\max \{0.02702 ; 0.05895 ; 0.10058 ; 0.12435\}=0.12435$

$\mathrm{y} 3+=\max \{0.21612 ; 0.17685 ; 0.06705 ; 0.06218\}=0.21612$ 
sehingga untuk solusi ideal positif menjadi, $A+=\{0.31958 ; \quad 0.12435 ; 0.21612\}$

Sementara itu, untuk solusi ideal negatifnya menggunakan bobot dari matrik keputusan yang telah di normalisasi maka solusi ideal negatif ditunjukkan di bawah ini:

$\mathrm{y} 1+=\operatorname{Max}\{0.37194 ; 0.38517 ; 0.38580 ; 0.31958\}=0.38580$

$\mathrm{y} 2+=\min \{0.02702 ; 0.05895 ; 0.10058 ; 0.12435\}=0.02702$

$y 3+=\min \{0.21612 ; 0.17685 ; 0.06705 ; 0.06218\}=0.06218$

sehingga untuk solusi ideal Negatif menjadi,

$\mathrm{A}^{-}=\{0.38580 ; \quad 0.02702 ; 0.06218\}$

Kemudian jarak untuk solusi ideal positifnya menggunakan alternatif terbaik dapat dilihat pada tabel berikut:

Tabel 10. Jarak Solusi Ideal Positif dengan Alternatif Terbaik

\begin{tabular}{|c|c|}
\hline Frekuensi (MHz) & Nilai \\
\hline 700 & 0.11052 \\
\hline 900 & 0.10060 \\
\hline 2400 & 0.16484 \\
\hline 5800 & 0.15394 \\
\hline
\end{tabular}

Tabel 10 menujukkan masing-masing nilai jarak antara alternatif sasaran dengan kriteria memiliki dampak yang paling positif (terbaik).

Sementara itu, jarak untuk solusi ideal positif menggunakan alternatif terburuk ditunjukkan pada tabel berikut:

Tabel 11. Jarak Solusi Ideal Positif dengan Alternatif Terburuk

\begin{tabular}{|c|c|}
\hline Frekuensi (MHz) & Nilai \\
\hline 700 & 0.15457 \\
\hline 900 & 0.11904 \\
\hline 2400 & 0.07372 \\
\hline 5800 & 0.11772 \\
\hline
\end{tabular}

Tabel 11 menujukkan jarak antara alternatif sasaran dengan kriteria memiliki dampak yang paling negatif (terburuk).

Sehingga dapat dilihat koefisien kedekatan menggunakan jarak alternatif terburuk dan jarak alternatif terbaik pada tabel berikut:

Tabel 12. Koefisien Kedekatan

\begin{tabular}{|c|c|}
\hline Frekuensi (MHz) & Nilai \\
\hline 700 & 0.58307 \\
\hline 900 & 0.54196 \\
\hline 2400 & 0.30904 \\
\hline 5800 & 0.43334 \\
\hline
\end{tabular}


Tabel 12 menunjukkan koefisien kedekatan, dihitung agar dapat menampilkan kinerja pemasok yang terbaik dengan masing-masing nilai frekuensi $700 \mathrm{MHz}=0.58307$, frekuensi $900 \mathrm{MHz}=0.54196$, frekuensi $2400 \mathrm{MHz}=0.30904$, dan frekuensi $5800 \mathrm{MHz}=0.43334$.

\section{KESIMPULAN}

Pada penelitian, ini Algoritma Fuzzy Topsis dapat digunakan menganalisa frekuensi yang terbaik yang dapat digunakan pada Project Loon. Hasil penghitungan menunjukkan matrik keputusan dengan normalisasi dan pembobotan yaitu frekuensi $700 \mathrm{MHz}$ memiliki nilai cakupan sebesar 0.37194 , bandwith 0.02702 , utilitas frekuensi sebesar 0.21612 . Jarak solusi ideal positif dengan alternatif terbaik pada frekuensi $700 \mathrm{MHz}$ yaitu sebesar 0.11052 , sedangkan untuk jarak solusi ideal positif dengan alternatif terburuk frekuensi $700 \mathrm{MHz}$ menunjukkan nilai 0.15457. Sementara itu untuk frekuensi $900 \mathrm{MHz}$ memiliki nilai cakupan sebesar 0.38517, bandwith sebesar 0.05895, dan utilitas frekuensi sebesar 0.17685. Adapun jarak solusi ideal positif dan alternatif terburuk frekuensi $900 \mathrm{MHz}$ adalah 0.10060 . Sementara itu untuk frekuensi $2400 \mathrm{MHz}$ memiliki nilai cakupan sebesar 0.38580, bandwith 0.10058 , dan utilitas frekuensi sebesar 0.06705 . Adapun jarak solusi ideal positif dengan alternatif terburuknya sebesar 0.16484. Sedangkan untuk frekuensi $5800 \mathrm{MHz}$ memiliki nilai cakupan sebsar 0.31958, bandwith 0.12435, dan utilitas frekuensi sebesar 0.06218. Jarak solusi ideal positif dan alternatif terburuknya sebesar 0.15394. Sehingga dapat disimpulkan bahwa frekuensi terbaik yang dapat digunakan oleh Project Loon ini adalah frekuensi 700 $\mathrm{MHz}$ dengan nilai koefisien kedekatan sebesar 0.58307. Frekuensi ini dipilih secara otomatis berdasarkan kriteria jarak, bandwidth, dan aplikasi-aplikasi yang berjalan pada frekuensi tersebut.

\section{DAFTAR RUJUKAN}

APJII. (2018). Asosiasi Penyelenggara Jasa Internet Indonesia. Buletin APJI edisi 22.

Asvial, M, S. Budiyanto, \& D. Gunawan. (2014). An intelligent load balancing and offloading in $3 \mathrm{G}$ - WiFi offload network using hybrid and distance vector algorithm, IEEE Symp. Wirel. Technol. Appl. ISWTA, (pp. 36-40).

Budiyanto, S, M. Asvial, \& D. Gunawan. (2014). Performance Analysis of Genetic Zone

Routing Protocol Combined With Vertical Handover Algorithm for 3G-WiFi Offload, J. ICT Res. Appl., $8(1), 49-63$.

Burr, J. (2017). The Feasibility of Google's Project Loon. Australia National University, 1-19.

Dammak, F, L. Baccour, \& A. M. Alimi. (2015). The impact of criterion weights techniques in TOPSIS method of multi-criteria decision making in crisp and intuitionistic fuzzy domains. IEEE International Conference on Fuzzy Systems, (pp. 1-8).

Google. (2019). How Loon Works - Project Loon - Google. Retrieved from www.google.com/loon/how/\#tab=envelope

Hakim, G. P. N, A. Firdausi, M. Alaydrus, \& S. Budiyanto. (2018). Dynamic Traffic Light Timing Control System using Fuzzy TOPSIS Algorithm. IOP Conference Series: Materials Science and Engineering, 453(1), 1-8.

$$
\text { ELKOMIKA - } 402
$$


Hwang, C. L, Lai, Y. J, \& Liu, T. Y. (1993). A new approach for multiple objective decision making. Computers and Operations Research, 20(8), 889-899.

Katikala, S. (2014). Google Project Loon. Rivier Academic Journal, 10(2), 3-8.

Propper, B. (2015). Inside Project Loon: Google's internet in the sky is almost open for business | The Verge. Retrieved from www.theverge.com.

Yuniarti, D, H. Hamjen, K. Ariansyah, A. Febian, S. Ariyanti, Kautsarina, ... R. A. Wahab. (2016). Kelayakan Implementasi High Altitude Platforms (HAPs). Jakarta: Badan Penelitian dan Pengembangan Sumber Daya Manusia Kementerian Komunikasi dan Informatika. 